\title{
Towards Effective Combination of Prior Knowledge and Cognitive Styles in Adaptive Educational Hypermedia Systems
}

\author{
http://dx.doi.org/10.3991/ijet.v7i3.2079 \\ F. Mampadi, P.A. Mokotedi \\ University of Botswana, Gaborone, Botswana
}

\begin{abstract}
Adaptive Educational Hypermedia Learning Systems (AEHS) have been developed and evaluated over the past decade. These AEHS tailored navigational support and presentation of content basing on either prior knowledge or cognitive styles of students separately. The empirical evaluations of the AEHS showed that, generally, there is positive improvement in the performance and perceptions of students. There is, however, a need to explore how prior knowledge and cognitive styles could be strategically combined in AEHS in order to maximize learning and comprehension of educational materials. To this end, this paper pursues this exploration by presenting results of a comparative analysis between two AEHS, one tailored to students' prior knowledge while the other to their cognitive styles, with emphasis on Pask's Holist-Serialist dimension. The comparative measure for this investigation is improvement in learning performance. A total of 104 students participated in the study, with 60 students using the prior knowledge version while 44 participated on the cognitive styles version. The findings indicated that the participants using the prior knowledge version outperformed those using the cognitive styles version basing on post-hoc tests. The implication of these results for the design of effective AEHS and recommendations are discussed by this paper.
\end{abstract}

Index Terms-Cognitive Styles, Prior Knowledge, Learning Performance, Adaptive Hypermedia System, HolistSerialist, e-learning

\section{INTRODUCTION}

An Adaptive Educational Hypermedia System (AEHS) tailors educational content to individual students by employing a user model built basing on parameters derived from human factors [2]. These human factors, in educational context, can range from gender differences [3] through prior knowledge [4,5] to cognitive styles [6,7]. Thus, human factors play an important role in the development of AEHS.

Among the aforementioned human factors, prior knowledge has been widely taken into account in the development of AEHSs. Furthermore, empirical evidence has suggested that matching students' prior knowledge with AEHSs can improve their learning performance [8],[9]. However, recent research has focused on cognitive styles as another human factor that can be used to drive adaptation in AEHSs. There has been a mixed reception of cognitive styles in AEHSs because research results have not shown consistency regarding its effectiveness in improving students' learning performance. Some studies have found that adapting to individuals' cognitive styles improves students' learning, such as [10],[11], while others showed that incorporating cognitive styles does not improve learning [8],[12]. Therefore, there is a need to investigate comparative effectiveness of the two individual differences, using learning performance as measure, prior to formulating ways of incorporating them in a single AEHS in order to maximize learning and comprehension.

Among various dimensions of cognitive styles, Pask's Holist-Serialist [13] is influential to student learning. Several studies, including [14] and [15], found that learning environments matched with the needs of Holists and Serialists could make them have better performance. Therefore, this study aims to examine the effects of an AEHS that provides an adaptation based on Pask's Holist/Serialist dimension and comparing to the one that provides adaptation based on levels of prior knowledge (i.e. novice and experts). More specifically, this study aims to prototype two AEHSs, one that adapts to a user's cognitive style (Holist-Serialist) and the other that adapt to the levels of prior knowledge. A thorough comparison based on learning performance is then conducted.

\section{RELATED RESEARCH}

\section{A. Adaptive Educational Hypermedia Systems}

Adaptive Educational Hypermedia Systems (AEHSs) have evolved from research in adaptive hypermedia which individualized content basing on certain characteristics of a user, like goals, interests, domain knowledge and other preferences. To achieve this, adaptive hypermedia represents these individual characteristics in a user model for adaptation [16]. The model is then updated as the user's goals and interests change with time or due to some other factors. Educational hypermedia was one of the first application areas of adaptive hypermedia because, in an educational context, users with alternative learning goals and knowledge require essentially different treatment [17]. For example, a student in an AEHS will be given a presentation that is adapted specifically to his or her knowledge of the subject [18] and a suggested set of most relevant links to proceed further [19].

A number of pioneer AEHSs were developed between 1990 and 1996. During that period, most researchers concentrated on building systems that adapt to their students' individual differences [18]. Classical adaptive hypermedia systems, including ELM-ART [20] and InterBook [21], have been created for educational settings, 
and tailor information to students' level of prior knowledge. Numerous studies have concluded that adapting to prior knowledge is an important approach to increase the effectiveness and efficiency of learning courses and might even increase users' satisfaction [22].

\section{B. Prior Knowledge and AEHSs}

Prior knowledge is another important variable that is related to hypermedia learning systems. Previous research indicates that prior knowledge can account for a high level of variance in most learning situations [23]. Individuals' prior knowledge in hypermedia learning includes previous understanding in the content area and levels of system experience appropriate to the program. Learners with high prior knowledge are normally referred to as "experts" while those with low prior knowledge are referred to as "novices". [24] developed a framework to integrate prior knowledge into the design of hypermedia learning systems in which they made a distinction between experts and novices. According to [25], an expert can simply be defined as an individual with formal training and experience in the area under investigation, whereas a novice can be defined as having little or no formal training/experience in the area examined. [26] argue that the contrast between experts and novices lies in the differences in the organisation of their conceptual structures: experts possess a mental representation (i.e. hierarchical structure) of the concepts in the domain, whereas a novice's structure is more chaotic and disordered. The different learning characteristics of experts and novices are summarized in Table 1.

In the past decade, a growing body of research has examined the influence of prior knowledge in hypermedia learning systems. Such research has suggested that different levels of prior knowledge suited to different types of content structure [28] and different navigation tools [29]. It demonstrates that prior knowledge can determine how well learners acquire information from hypermedia and can influence their learning patterns in a hypermedia system [4]. [30] illustrate the interaction of prior knowledge with hypermedia learning by presenting a review of relevant research covering 26 quantitative and qualitative studies from 1990 to 2003. In particular, the review focused on four themes - (1) disorientation problems; (2) content structure; (3) navigation tools; and (4) additional support - as they are considered to be important issues pertaining to hypermedia learning in the literature. Table 2 shows summary of preferences for novice and expert users derived from their study.

A number of researchers have examined the effect of prior knowledge in AEHS. For example, [31] used an authoring system NetCoach, which provides a way to assess the users' prior knowledge and to adapt the course in different ways, to investigate the effectiveness and efficiency of learning courses that provide adaptation. Each NetCoach course implements several adaptive features that require an adequate assessment of the prior knowledge. Based on this information, NetCoach infers the user's knowledge about each chapter and decides how to adapt. Therefore, NetCoach supports the two concept relations prerequisite and inference [32]. The results of

This paper is sponsored by the University of Botswana:

Corresponding Author: mampadif@mopipi.ub.bw. Tel: +267 74213026
TABLE I.

DIFFERENCE LEARNING CHARACTERISTICS OF EXPERTS AND NOVICES (ADAPTED FROM [27])

\begin{tabular}{|c|c|}
\hline Experts & Novices \\
\hline 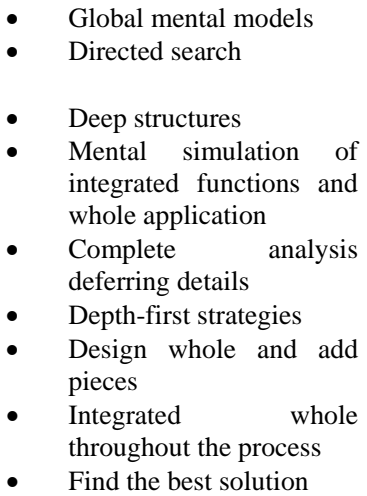 & $\begin{array}{ll}\text { - } & \text { Local mental models } \\
\text { - } & \text { Undirected search (trial } \\
\text { and error) } \\
\text { - } & \text { Surface structures } \\
\text { - } & \begin{array}{l}\text { Mental simulation of } \\
\text { isolated functions }\end{array} \\
\text { - } & \text { Incomplete analysis } \\
\text { - } & \text { Breadth-first strategies } \\
\text { - } & \text { Design pieces } \\
\text { - } & \text { Failure to integrate pieces } \\
\text { into a whole } \\
\text { - }\end{array}$ \\
\hline
\end{tabular}

TABLE II.

SUMMARY OF PREFERENCES FOR NOVICE AND EXPERT USERS (FROM [30])

\begin{tabular}{cccc}
\hline & Novices & Experts \\
\hline & Perform better in & $\bullet$ & Perform better in network \\
hierarchical structure & & structure \\
- & Need advance organizers & & Pad advertisement \\
a & Prefer guided navigation & & \\
- & Prefer concept maps & & \\
\hline
\end{tabular}

the study indicated that adapting to prior knowledge is an important approach to increase the effectiveness and efficiency of learning courses and might even increase the users' satisfaction.

\section{Cognitive Styles and AEHS}

Recent research has shifted to the exploration of incorporating cognitive styles in the adaptivity of educational hypermedia systems, such as INSPIRE [33] and AES-CS [34]. Cognitive style, which is a term used in cognitive psychology, describes the way individuals think, perceive and remember information, or their preferred approaches to using such information to solve problems [35]. Cognitive style is sometimes used interchangeably with learning styles. However, [36] and [33] note that learning styles are the cognitive, affective, and psychological traits that serve as relatively stable indicators of how learners perceive, interact with, and respond to the learning environment. In other words, cognitive styles and learning styles are not fully the same [37].

Several dimensions of cognitive styles have been studied in the past century, including Holist-Serialist [38], Wholist-Analytical [39], Verbaliser-Imager [40], and Field Dependence-Field Independence [41]. Among them, Field Dependence/Independence (FD/FI) has emerged as the most widely studied, with the broadest application in education [6]. Recently, this dimension of cognitive style was considered in the development of AEHSs [8]. The other dimension of cognitive style, i.e., Pask's HolistSerialist [13], has a conceptual link with FD/FI [6]. Similar to FD learners, Holists process information in relatively global ways in that they tend to build an overall picture of the subject area. Conversely, Serialists take a similar learning pattern of FI learners, tending to maintain 
a local focus, concentrating on one thing at a time, and on building up procedural understanding step by step.

Holist-Serialist is a dimension of cognitive style identified by Pask [38]. Pask and his colleagues conducted a series of experiments [42] to determine learners' basic approaches in learning a range of complex academic topics by monitoring routes taken by learners through the topics. The experiments were set up such that the participants used one of two basic approaches, which are the global and the local approaches. In the global learning approach, termed "Holist", learners examined the interrelationships between several topics early in the learning process. They built a broad conceptual overview into which detail could subsequently be fitted. In the local learning approach, termed "Serialist", learners examined one thing at a time, and concentrated on separate topics and the logical sequence linking them. Pask found that individuals were consistent in their use of strategies of Holists or Serialists. [43] summarized the differences between Holists and Serialists, as shown in Table 3.

A number of studies found that Holists and Serialists showed different preferences to the use of hypermedia systems. For example, [44] found significant differences in navigational tools used by Holists and Serialists. The Holists made greater use of the concept map while the Serialists of the keyword index. Additionally, [10] found that Holists spent a greater proportion of their time browsing high in the hypertext hierarchy, which was explained in terms of Holists being dependent on a need to grasp a sense of the structure of the hypertext, which differ from the browsing strategies displayed by Serialists, which did not appear to be indicative of such a need. In addition to the aforementioned works, [45] also identified the differences in the needs of Holists and Serialists in hypermedia learning, which are summarized in Table 4.

As shown in Table 4, Holists and Serialists have very different preferences, also Table 4 shows that novice and expert users have different preferences. Thus, it is necessary to develop AEHSs, which one matches with the preferences of Holists and Serialsts, and the other matches with preferences of Novices and Experts. To this end, based on the findings in Table 4 and, we developed two AEHSs each exhibiting two types of interfaces: one AEHS has interfaces that adapt to Holists and Serialists while the other AEHS had interfaces that adapt to Novices and Experts. Prior to this study, two studies were conducted that checked whether the developed AEHSs influence learning performance [9], [46]. The results of the studies showed that both AEHSs improved learning performance. However, the studies did not make a comparative analysis to determine which of the two improved learner performance more than the other. In this vein, this study addresses this issue by investigating the research question: Whether adapting hypermedia learning system to an individual's Holist-Serialist dimension shows any differences in learning performance when compared to adapting hypermedia learning system to an individual's prior knowledge.

\section{EXPERIMENTAL DESIGN}

\section{A. Participants}

104 participants from Brunel University took part in this experiment. 60 students participated in the prior
TABLE III.

DIFFERENCES BETWEEN HOLISTS AND SERIALISTS (DERIVED FROM [43])

\begin{tabular}{|c|c|}
\hline Holists & Serialists \\
\hline $\begin{array}{l}\text { - } \quad \text { Pick up bits and pieces } \\
\text { with a broad framework } \\
\text { - } \quad \text { May leave gaps, or repeat } \\
\text { themselves } \\
\text { - } \quad \text { May make mistakes } \\
\text { about connections be- } \\
\text { tween things } \\
\text { - } \quad \text { May over-generalise } \\
\text { - May be more comfort- } \\
\text { able with "topic" based } \\
\text { learning }\end{array}$ & $\begin{array}{l}\text { Build up their knowledge } \\
\text { sequentially } \\
\text { - } \quad \text { Tend to lose sight of the } \\
\text { bigger picture } \\
\text { - } \quad \text { Are impatient with co- } \\
\text { workers who" jump } \\
\text { around” } \\
\text { Are more comfortable } \\
\text { with inherently sequential } \\
\text { problem-solving }\end{array}$ \\
\hline
\end{tabular}

TABLE IV.

PREFERENCES OF HOLISTS VS. SERIALISTS (ADAPTED From [45])

\begin{tabular}{cccc}
\hline \multicolumn{2}{c}{ Holists } & \multicolumn{2}{c}{ Serialists } \\
\hline Characteristic & Preference & Characteristic & Preference \\
\hline Passive & Rely on a & Active & Prefer to use \\
approach & map to & Approach & index to \\
& impose & & locate \\
& mental & & specific \\
& structure & & items \\
Global & Prefer & Analytical & Prefer \\
tendency & breadth-first & Tendency & depth-first \\
& paths & & paths \\
Internally & Prefer non- & Externally & Prefer linear \\
directed & linear and & directed & and \\
& flexible & & restricted \\
& navigation & & navigation \\
\hline
\end{tabular}

knowledge version while 44 participated in the cognitive styles version experiment respectively. The age group of the participants ranged between 18 and 30. The sample represented students from Information Systems and Computing, Mathematics and Engineering that included both undergraduate and post graduate students. The participants were chosen from such diverse disciplines and different levels of courses so that the bias of a particular type of domain knowledge or course could be reduced.

\section{B. Instruments}

a) Adaptive Educational Hypermedia System: Prior Knowledge

An AEHS was prototyped, containing material on introduction to XML. The content was designed to cater for the needs of both novice and expert learners. The content was on the same topics, however, experts were provided with material that was more advanced while novices were provided with less advanced material which was accompanied by additional explanations.

The adaptive hypermedia system was designed to allow for non-linear learning, but with navigation and presentation structures that have been researched and empirically proven to benefit either low prior knowledge or high prior knowledge individuals. To achieve this, we utilised AHA! (Adaptive Hypermedia Architecture), which is a system built with the aim of making it easy to generate adaptive courses for the Web [47]. The adaptation in AHA! is carried out based on a series of rules included in the HTML pages. There are rules defined by the creator of the course that are used to determine what parts of the page are shown to the student. The conditions in the rules 
included in the pages are based on certain characteristics that the users describe about themselves. These characteristics are kept in a very simple User Model (which says which concepts were learned by the user, or which interface preferences they have), which the designer can also create in the course using XML documents. AHA! uses note-taking techniques, discarding, hiding and adaptive link eliminations. The actual version of AHA! is 3.0 which includes authoring tools that facilitate the creation of courses. The incorporation of authoring tools makes AHA! as an ideal candidate for creating Adaptive OnLine Courses. The fact that AHA! is an open source also makes it an ideal candidate as the core system component that could be extended to suit the need of the experiment.

We, therefore, created and implemented several extensions and changes to the source code to achieve our desired functionality.

- Pre-test and post-test components for more accurate evaluation of students' were developed using JavaScripts.

- The sub-component that adapts to low prior knowledge employed most, if not all, of the AHA! functionality.

- For the system to adapt to individuals with high prior knowledge, we developed a component that uses an index, instead of hierarchical content structure offered by the treeView components of AHA!

The adaptive hypermedia system included 31 pages and the content was divided into 13 sections. There were significant differences between the interfaces for novices and experts, adapted from an ordinary interface based on the findings from previous research [48],[49] summarised in Table 5.

TABLE V.

THE DIFFERENCES BETWEEN NOVICES’ AND EXPERTS' INTERFACES

\begin{tabular}{|l|l|l|}
\hline $\begin{array}{l}\text { Adaptive } \\
\text { Hypermedia }\end{array}$ & $\begin{array}{l}\text { Novice Inter- } \\
\text { face }\end{array}$ & $\begin{array}{l}\text { Expert Inter- } \\
\text { face }\end{array}$ \\
\hline Link hiding & Hidden links & Rich links \\
\hline Adaptive layout & Hierarchical Map & Alphabetic Index \\
\hline Additional support & Advisements light & No advisements \\
\hline Annotated Links & $\begin{array}{l}\text { Traffic annotations } \\
\text { metaphor }\end{array}$ \\
\hline
\end{tabular}

As described in Table 5, four types of adaptive hypermedia techniques were applied to develop these two interfaces, and their detailed functionalities are described below:

- Link Hiding: The idea of links hiding, which was used in the novices' interface, is to limit the navigation space and reduce the cognitive load by hiding all links to the nodes that the student is not expected to learn. There are two kinds of these links: links to notready-to-be-learned nodes and links to the nodes that are outside the users' current goal. AHA! implements this adaptive technique for its content. For the links in the content, blue links meant the material behind the link was ready to be learnt, purple for learnt (or visited) material and black (similar to text, i.e. hidden) meant for material which the learner was deemed not ready to learn.

- Adaptive Layout: Because novice and expert users process information in different ways, adaptive lay- out was applied to identify the relationships of the subject topics by providing different tools. The novice interface provided a hierarchical map, which could help novices to understand the content structure. Conversely, the high prior knowledge interface used an index to facilitate the location of specific information. These tools allowed users to go directly to any page of the system, and were located in the top left-hand corner, within the sidebar.

- Additional Support: This was implemented in AHA! in the form of advisements and visual cues that recommended some links based on learners' prior knowledge. Furthermore, the navigational aids were used to help novices ease disorientation problems.

- Annotated Links: The links for low prior knowledge students were annotated to support local orientation by providing information about the current state of nodes behind the annotated links.

For experts, the guidance through the material was negligible. An index was used to navigate through topics, instead of a hierarchical map employed for novices. The content was more detailed and more advanced with links that were not annotated. The links showed only the standard browsers distinction between visited and unvisited modes.

\section{b) Adaptive Educational Hypermedia System: Cognitive Styles}

The Adaptive Educational Hypermedia System (AEHS) presents an introduction of XML (eXtensible Markup Language). The two versions of the AEHS presents the same content, but appropriate adaptive techniques were used to adapt the content to the needs of Holists or Serialists.

The AEHS was designed to allow for non-linear learning, but with navigation and presentation structures that have been researched and empirically proven to benefit either Holists or Serialists. AHA! [18] was utilized in the development of the prototype. However, it was extended for suitability of this study. We, therefore, created and implemented some extensions and changes to the source code of the 'open source' AHA! to achieve our functionality, that is adapting to Holists and Serialists:

- The pre-test and post-test were incorporated into the AHA! as sub-components.

- The system component that adapts to Holist was developed by modifying the collapsible treeView of AHA! representing the table of contents and replacing it with an expanded view.

- For the Serialist component, we developed a system that had an index, instead of the expanded table of contents view employed for the Holist component.

- The Study Preference Questionnaire (SPQ) developed by [14] was developed as an online component using Javascript and incorporated into the system.

The system included 31 pages and the content was divided into 13 sections as in the prior knowledge version. However there are significant differences between the interfaces developed for Holists and Serialists respectively. Both interfaces were built based on the findings from previous research summarized in Table 4. Three types of adaptive hypermedia techniques were applied to 
develop these two interfaces, and their detailed functionalities are described in Table 6.

- Direct guidance: Direct guidance is the most simple technique or technology of adaptive navigation support. It is taken from intelligent tutoring systems and is usually implemented through the "next" button for the systems to suggest the best next unit of information to visit according to the user's goals and other parameters in the user model. Pask's experimental studies [38] show that the Holist is cognitively complex and likes to have several things "on the go" at the same time. In contrast to the steady "brick-bybrick" approach of the Serialist, the Holist adopts a comparatively high risk, exploratory strategy, switching attention across a range of tasks before any one is securely completed and checked as a sure foundation of further progress. This, therefore, requires no guidance that would restrict their "jumping around" approach. On the other hand, the Serialists have a narrow focus and follow a step-by-step logical progression, making sure to build solid foundations for each next move. Hence direct guidance using NEXT/PREVIOUS or BACK/ FORWARD buttons was seen as viable for the Serialist interface.

- Link disabling: Due to the fact that Serialist users become disoriented and prefer a linear navigation strategy, the Serialist interface provided restricted navigation choices whereby links within the body of the page were disabled, hence displayed as normal text. On the other hand, the Holist interface provided rich links within the main body of the text, leaving freedom of navigation to the users.

- Adaptive layout: Because Holist and Serialist users process information in different ways, an adaptive layout was applied to identify the relationships of the subject topics by providing different tools. The Holist interface provided a hierarchical map, which could help Holists to understand the content structure. Conversely, the Serialist interface used an alphabetical index to facilitate the location of specific information [44]. These tools allowed users to go directly to any page of the system and were located in the top left-hand corner, within the sidebar.

c) Study Preferences Questionnaire (SPQ)

In an attempt to devise a relatively quick and easy measure of Holist and Serialist biases, [14] has produced the Study Preferences Questionnaire (SPQ), which is an 18-item inventory for categorizing learners as Holists or Serialists. To this end, students were provided with two sets of statements. They were asked to indicate their degree of agreement with either statement, or to indicate no preferences [14]. As the SPQ has been used in several studies, such as [44] and [10], it was chosen for this study, which identified Holists and Serialists by using criteria suggested by the original producer [14]: (a) if users agree with over half of the statements related to Holists, they are treated as Holists; and (b) if users agree with over half of the statements related to Serialists, they are then considered Serialists.

\section{d) Pre- and Post-tests}

Pre- and post-tests were written to assess the participants' level of knowledge of the subject domain both before and after using the systems. The pre-test gave an
TABLE VI.

THE DIFFERENCES BETWEEN HOLIST AND SERIALIST INTERFACES

\begin{tabular}{ccc}
\hline $\begin{array}{c}\text { Adaptive } \\
\text { Hypermedia }\end{array}$ & $\begin{array}{c}\text { Holist Inter- } \\
\text { face }\end{array}$ & $\begin{array}{c}\text { Serialist } \\
\text { Interface }\end{array}$ \\
\hline Guidance & No guidance & Next/ Previous \\
& & Buttons \\
Link hiding & Rich links & Disabled links \\
Adaptive layout & Hierarchical Map & Alphabetic Index \\
\hline
\end{tabular}

objective assessment of the participants' prior knowledge of the subject domain, as opposed to the subjective measure given by their responses to the questionnaires. Each test contained 19 multiple choice questions covering content of XML. For each question, there were five possible responses: four different answers and a "don't know" option. The questions were matched on the preand post-tests so that each question on the pre-test had a corresponding similar (but not the same) question on the post-test. Creating similar questions was achieved by either re-writing the question or changing the answer options to TRUE/FALSE and “don't know”. The questions in the post-test were also shuffled so that the number sequence was different from the pre-test.

\section{EXPERIMENTAL PROCEDURES}

In order to determine whether or not the AEHS adapting to prior knowledge (i.e. PAEHS) was better, with respect to learning performance, than the AEHS adapting cognitive styles (i.e. CAEHS), a between-subjects design was used. In other words, this meant that each student used either of the systems once but not both. The experiment was controlled. The same content was used for both systems without incurring the practice and fatigue effects in the experiment. Furthermore, each participant went through the same procedures in order to minimize bias. The following procedures were followed:

- At the beginning of each experiment, the subjects were briefed about the functionality of the system and the available tools that can be utilized to aid learning. This explanation about the functionality of the system was meant to minimize the gap between system experiences of participants as they were from diverse backgrounds and previous research has shown that system experience can have an effect on learning performance and perceptions [10],[5].

- For both PAEHS and CAEHS the subjects were then asked to, carefully, go through a pre-test which consisted of 19 questions to measure their initial levels of knowledge. To draw participants' attention to details, answers could not be changed once they have been given. The system also allowed participants to continue to the next level once all questions have been answered.

- Furthermore, for the CAEHS the subjects were automatically provided with the Study Preference questionnaire (SPQ) to determine whether the subjects are Holists or Serialsts. Subsequently, the right version of the adaptive hypermedia system was presented based on the results of the SPQ.

- When the participants had studied the material, they could then follow a link to do the post-test before filling an exit questionnaire. 


\section{RESUlTS AND DISCUSSIONS}

Summary of the t-test results related to students' learning performances are shown in table 7 . The t-test results indicate that there was no significant difference in learning performance between users of prior knowledge Adaptive Educational Hypermedia System and those that used the cognitive styles Adaptive Educational Hypermedia System, $t(46)=-1.256, p=.215$. That is, the average performance (gain score) of students using the prior knowledge adaptive system $(M=30.15$, SD $=19.396)$ was not significantly different from that of students using the cognitive styles adaptive system $(M=36.64$, $\mathrm{SD}=$ 15.735).

The t-test results also indicated that there was no significant difference in post-test score between user of prior knowledge Adaptive Educational Hypermedia System and those that used the cognitive styles Adaptive Educational Hypermedia System, $t(46)=1.191, p=.240$. That is, the average performance score of prior knowledge $(M=$ $72.65, \mathrm{SD}=12.096)$ was not significantly different from that of men $(M=68.64, \mathrm{SD}=11.074)$.

However, because there are different groups within the two broad groups of prior knowledge and cognitive styles, a further investigation of the differences in means between the lower level groups was conducted, and the results of the one-way ANOVA are shown in Table 8. The results show that, with respect to post-test score, there is no significant difference between the groups (novice, expert, Holist and Serialist). The p-value for the $F(3,44)=.935$ is .432, which is the chosen cut-point for significance. However, the results for the gain in knowledge, shown by the gain score shows that there is significant difference across group means. The p-value for $F(3,44)=8.633$ is .000 . This does not tell us which groups contribute to the significant difference. Hence multiple comparisons were done to determine the relationships between the group means.

The multiple comparisons of means were performed using the Bonferroni post-hoc tests and the summary of results shown in Table 9. The results show that, with respect to post-test scores, there were no significant differences between prior knowledge groups and the cognitive styles groups. However, the results show that both the Holists and Serialists gained more than the experts in the prior knowledge groups.

In order to get a clear picture of the differences in across group means a plot of the means is shown by Figure 1. It shows clearly that experts performed less that all the other groups, with novice gaining more knowledge than Holists and Serialists as well. Hence the significant differences demonstrated by the one-way ANOVA could be accounted to the lack of gain of knowledge by experts using an Adaptive Educational Hypermedia System that adapts to their level of prior knowledge.

The mean plot of the post-test scores for the groups in Figure 1, although not statistically significantly different, we observed that the prior knowledge group gained higher scores than the cognitive styles group. That is, both novice and experts performed better than the Holists and Serialists in post-test. The mean plots for the gain scores in Figure 2 also show a pictorial indication that novices benefited more than the cognitive styles groups.
TABLE VII.

STUDENTS’ LEARNING OUTCOMES (T-TEST)

\begin{tabular}{cccc}
\hline Variables & $\begin{array}{c}\text { Prior } \\
\text { Knowledge } \\
\text { Mean (SD) }\end{array}$ & $\begin{array}{c}\text { Cognitive } \\
\text { Styles } \\
\text { Mean } \\
(\mathrm{SD})\end{array}$ & $\begin{array}{c}\text { Significance } \\
\mathrm{t}(\boldsymbol{p})\end{array}$ \\
\hline $\begin{array}{cccc}\text { Post-test } \\
\text { Scores }\end{array}$ & $72.65(12.096)$ & $\begin{array}{c}68.64 \\
(11.074)\end{array}$ & $1.191(.240)$ \\
\cline { 1 - 1 } Gain Scores & $30.15(19.396)$ & $\begin{array}{c}36.64 \\
(15.735)\end{array}$ & $-1.256(.215)$ \\
& & & \\
\hline
\end{tabular}

TABLE VIII.

STUDENTS LEARNING OUTCOMES (ONE-WAY ANOVA)

\begin{tabular}{llllll}
\cline { 2 - 6 } & \multicolumn{2}{l}{$\begin{array}{l}\text { Prior Knowledge } \\
\text { Mean }(S D)\end{array}$} & \multicolumn{2}{l}{$\begin{array}{l}\text { Cognitive Styles } \\
\text { Mean }(S D)\end{array}$} & Significance \\
\cline { 2 - 6 } & Novice & Expert & Holist & Serialist & $\mathrm{F}(\boldsymbol{p})$ \\
\hline $\begin{array}{l}\text { Post- } \\
\text { test }\end{array}$ & 72.53 & 72.82 & 71.33 & 65.40 & .935 (.432) \\
Scores & $(14.515)$ & $(8.412)$ & $(11.428)$ & $(10.255)$ & \\
\cline { 1 - 3 } $\begin{array}{l}\text { Gain } \\
\text { Scores }\end{array}$ & & & & & \\
\hline
\end{tabular}

TABLE IX.

BONFERRONI POST-HOC TESTS FOR MULTIPLE COMPARISONS OF STYLES

\begin{tabular}{|c|c|c|c|c|c|}
\hline & & $\begin{array}{c}\text { Novice/ } \\
\text { Holist }\end{array}$ & $\begin{array}{l}\text { Novice/ } \\
\text { Serialist }\end{array}$ & $\begin{array}{c}\text { Expert/ } \\
\text { Holist }\end{array}$ & $\begin{array}{l}\text { Expert/ } \\
\text { Serialist }\end{array}$ \\
\hline \multirow{3}{*}{$\begin{array}{c}\text { Post } \\
- \\
\text { Test }\end{array}$} & $\begin{array}{c}\text { Mea } \\
n\end{array}$ & $\begin{array}{c}1.200 \\
(4.538)\end{array}$ & $\begin{array}{c}7.133 \\
(4.783)\end{array}$ & $\begin{array}{c}1.485 \\
(4.891)\end{array}$ & $\begin{array}{c}7.418 \\
(5.119)\end{array}$ \\
\hline & $\begin{array}{c}\text { Diff } \\
\text { (Std } \\
\text { Er- } \\
\text { ror) }\end{array}$ & & & & \\
\hline & Sig. & 1.000 & .858 & 1.000 & .927 \\
\hline \multirow{3}{*}{$\begin{array}{c}\text { Gai } \\
\text { n } \\
\text { Scor } \\
\text { e }\end{array}$} & $\begin{array}{c}\text { Mea } \\
n\end{array}$ & $\begin{array}{c}6.050 \\
(5.693)\end{array}$ & $\begin{array}{c}4.833 \\
(6.001)\end{array}$ & $\begin{array}{c}-22.265 \\
(6.136)\end{array}$ & $\begin{array}{l}-23.482 \\
(6.423)\end{array}$ \\
\hline & $\begin{array}{c}\text { Diff } \\
\text { (Std } \\
\text { Er- } \\
\text { ror) }\end{array}$ & & & & \\
\hline & Sig & 1.000 & 1.000 & .004 & .004 \\
\hline
\end{tabular}

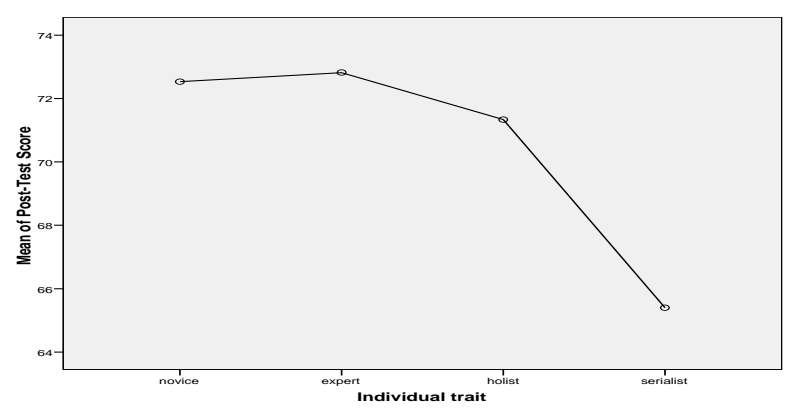

Figure 1. Mean plots for post-test scores based on style

Therefore, with respect to learning performance, in the design of Adaptive Educational Hypermedia Systems, it is evident, from the results, that an effective learning hypermedia system would require an implementation of a learning model which drives the learning process. This argument is supported by the results which indicate that novices, in general, benefited more than the rest of the groups. The benefit was driven by the pre-requisite-based help employed by AHA [47], which was not implemented in Adaptive Educational Hypermedia System that adapts to cognitive styles. This model can perhaps be most useful 


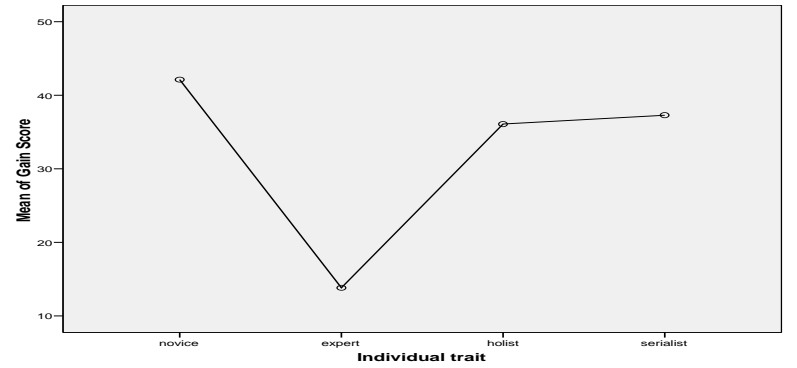

Figure 2. Mean plots for gain scores

in assisting a learner with difficult or ill-understood topics. It has to be noted that novices can be either Holists or Serialists. The question will be whether the provision of the pre-requisite structure could beneficial to adaptation to cognitive styles.

\section{CONCLUSIONS}

The purpose of research was to determine whether the Adaptive Educational Hypermedia Systems matched with users' prior knowledge and those matched with users' cognitive styles show different effects on users' learning performance. The results of the Post-test scores did not show any differences between the prior knowledge and cognitive styles groups. However, the Gain scores (scores differences between Post-test and Pre-test) suggested that there are different effects on learning performance of students using the prior knowledge version as compared to those using the cognitive styles version. The results showed that students using the prior knowledge version outperformed the students using the cognitive styles version basing on the post-hoc tests. Comparing these results to previous research with the same goals proved difficult because comparative analysis of this type had not been performed. However, finding from both [9] and [46] suggest that both prior knowledge and cognitive styles, generally, have an effect on learning performance but comparisons between prior knowledge and cognitive styles were not exclusively made.

These results suggest that there should be a way of adapting to both prior knowledge and cognitive styles in a single adaptive hypermedia system in order to maximize on line educational learning. Therefore, there is a need to investigate how the two individual characteristics influence other measures that affect performance, like perceptions and attitudes of learners. This should be done prior to investigating their effective combination in Adaptive Educational Hypermedia Systems. A framework for such a combination could, therefore, be developed.

\section{ACKNOWLEDGMENT}

I would like to thank the Department of Computer Science and the University of Botswana for sponsoring the presentation costs of this paper. I also would like to thank Prof Sherry Y. Chen who is now at Graduate Institute of Network Learning Technology, National Central University, Taiwan for guiding me through my research while she was at Brunel University during the process of completing my $\mathrm{PhD}$ thesis.

\section{REFERENCES}

[1] P. Brusilovsky, KnowledgeTree: A distributed architecture for adaptive e-learning. In: Proceedings of The Thirteenth Interna- tional World Wide Web Conference, WWW 2004 (Alternate track papers and posters), New York, NY, 17-22 May, 2004, ACM Press, pp. 104-113.

[2] H. Alomyan, Individual differences: implications for web-based learning design, J Int Educ 4 (4) (2004), pp. 188-196.

[3] P. Schumacher, \& J. Morahan-Martin, Gender, Internet and computer attitudes and experiences. Computers in Human Behavior, 17, (2001), 95-110. http://dx.doi.org/10.1016/S07475632(00)00032-7

[4] D. A. Last, A. M. O_Donnell, \& A. E. Kelly, (2001). The effects of prior knowledge and goal strength on the use of hypermedia. Journal of Educational Multimedia and Hypermedia, 10(1), (2001), 3-25.

[5] T. J. F. Mitchell, S. Y. Chen, and R. D. Macredie, Hypermedia Learning and Prior Knowledge: Domain Expertise vs. Systems Expertise, Journal of Computer Assisted Learning 21 (1) : (2005b) 53-64 http://dx.doi.org/10.1111/j.1365-2729.2005.00113.x

[6] S. Y. Chen, and R. D. Macredie, Cognitive Modelling of Student Learning in Web-Based Instructional Programs, International Journal of Human-Computer Interaction 17 (3) : (2004) 375-402

[7] N. Stash, P. De Bra, Incorporating cognitive styles in AHA! (The Adaptive Hypermedia Architecture). In Proceedings of the International Conference Web-Based Education (pp. 378-383). (2004) Innsbruck, Austria.

[8] T.F.J. Mitchell, S.Y. Chen, and R.D. Macredie, Cognitive Styles and Adaptive Web-Based Learning, Psychology of Education Review 29 (1) : (2005a),34-42

[9] F. Mampadi, S.Y. Chen, and G. Ghinea, The Effects of Prior Knowledge on the Use of Adaptive Hypermedia Learning Systems. HCI International, HCI (4)'2009. pp.156 165

[10] F. Ford, \& S.Y. Chen, Individual differences, hypermedia navigation and learning: An empirical study. Journal of Educational Multimedia and Hypermedia, 9(4), (2000), 281-312.

[11] F. Mampadi, Comparative students' perceptions and attitudes towards adaptive hypermedia learning systems: prior knowledge vs. cognitive styles. Edulearn11 proceedings, July 2011: pp 56965705

[12] N. Tsianos, P. Germanakos, \& C. Mourlas, Assessing the Importance of Cognitive Learning Styles over Performance in Multimedia Educational Environments, Proceedings of the 2nd International Conference on Interdisciplinarity in Education (ICIE2006), Athens, May 11-13, 2006

[13] N. Bajraktarevi, W. Hall, and P. Fullick, Incorporating learning styles in hypermedia environment: Empirical evaluation. In: Proceedings of AH2003: Workshop on Adaptive Hypermedia and Adaptive Web-Based Systems, Budapest, Hungary (41-52)

[14] N. Ford, Learning styles and strategies of postgraduate students. British Journal of Educational Technology, 16, (1985), 65-79. http://dx.doi.org/10.1111/j.1467-8535.1985.tb00483.x

[15] M. Kwok, and C. Jones, Catering for different learning styles. Association for Learning Technology Journal (ALT-J), 3, 1, (1985) pp. 5-11.

[16] A. Kavcic, The Role of User Models in Adaptive Hypermedia Systems, Proceedings of the $10^{\text {th }}$ Mediterranean Electrotechnical Conference MEleCon 2000, Lemesos, Cyprus, May 2000.

[17] P. Brusilovsky, and C. Peylo, Adaptive and Intelligent Web-based Educational Systems. International Journal of Artificial Intelligence in Education 13, 2003, 156-169.

[18] P. De Bra, and L. Calvi,AHA: a Generic Adaptive Hypermedia System, Proceedings of the Second Workshop on AdaptiveHypertext and Hypermedia, pp. 5-11, Pittsburgh, 1998.

[19] P. Brusilovsky, Adaptive navigation support in educational hypermedia: The role of student knowledge level and the case for meta-adaptation. British Journal of Educational Technology, 34(4), 2003, 487-497. http://dx.doi.org/10.1111/1467-8535.00345

[20] G. Weber, and P. Brusilovsky, ELM-ART: An adaptive versatile system for Web-based instruction International Journal of Artificial Intelligence in Education 12, 4, (2001), 351-384.

[21] P. Brusilovsky, J. Eklund, and E. Schwarz, Web-based education for all: A tool for developing adaptive courseware. Proceedings of Seventh International World Wide Web Conference, 14-18 April 1998, 291-300. 
[22] C. Boyle, and A.O. Encarnacion, MetaDoc: An adaptive hypertext reading system. User Modeling and User-Adapted Interaction, 4(1), (1994) 1-19. http://dx.doi.org/10.1007/BF01142355

[23] S. Tobias, Interest, prior knowledge, and learning. Review of Educational Research, 64 (1), (1994), 37-54.

[24] S.Y. Chen, J.P. Fan, \& R.D. Macredie, Navigation in hypermedia learning systems: Experts vs. novices. Computers in Human Behavior, 22, (2006) 251-266. http://dx.doi.org/10.1016/ j.chb.2004.06.004

[25] P. Simmons, \& V. Lunetta, Problem-solving behaviors during a genetics computer simulation: beyond the expert/novice dichotomy. Journal of Research in Science Teaching, 10, (1993), 153173. http://dx.doi.org/10.1002/tea.3660300204

[26] J.P. Fan, "Interface Design for Hypermedia Learning Systems: A Study Individual Differences and Hypermedia Systems Features”, PhD Thesis, Brunel University, 2005.

[27] F. Calisir, \& Z. Gurel, Influence of text structure and prior knowledge of the learner on readingcomprehension, browsing and perceived control. Computers in Human Behavior, 19(2), (2003), 135-145. http://dx.doi.org/10.1016/S0747-5632(02)00058-4

[28] S. McDonald, S., \& R.J. Stevenson, Navigation in hyperspace: An evaluation of the effects of navigational tools and subject matter expertise on browsing and information retrieval in hypermedia. Interacting with Computers, 10, (1998) 129-142. http://dx.doi.org/10.1016/S0953-5438(98)00017-4

[29] S.Y. Chen, J.P. Fan, \& R.D. Macredie, Navigation in hypermedia learning systems: Experts vs. novices. Computers in Human Behavior, 22, (2006) 251-266. http://dx.doi.org/10.1016/i.chb.2004. $\underline{06.004}$

[30] S. Weibelzahl, \& G. Weber, Adapting to prior knowledge of learners. In de Bra, P., Brusilovsky, P., \& Conejo, R. (Eds.), Proceedings of the second international conference on Adaptive Hypermedia and Adaptive Web Based Systems, Malaga, Spain, AH2002 (pp. 448-451). Berlin: Springer.

[31] G. Weber, H.C. Kuhl, and S. Weibelzahl, "Developing adaptive internet based courses with the authoring system NetCoach". Proceedings of the Third International Workshop on Adaptive Hypermedia, Sonthofen, Germany, July 2001.

[32] K.A. Papanilolaou, M. Grigoriadou, H. Kornilakis, G.D. Magoula, Personalising the interaction in a Web-based educational hypermedia system: the case of INSPIRE. User-Modeling and UserAdapted Interaction 13 (3), (2003), p213-267 http://dx.doi.org/ 10.1023/A:1024746731130

[33] E. Triantafillou, A. Pomportsis, S. Demettradis, E. Georgiadou, The value of adaptivity based on cognitive style: an empirical study. British Journal of Educational Technology, 35(1), 2004, 95-106 http://dx.doi.org/10.1111/j.1467-8535.2004.00371.x

[34] R. Riding, \& S. Rayner, Cognitive Styles and learning strategies. London: David Fulton Publishers, (1998).

[35] G.H. Zamani-Zarghani, Identification of learning style strategies which enable college students with differing personality temperament to cope with learning blocks (Doctoral dissertation, Univer- sity of Nebraska - Lincoln, 1988). Dissertation Abstracts International, 49(10), 2920A. (University Microfilms No. AAC88-24960)

[36] D.H. Jonassen, and B.L. Grabowski, Editors, Handbook of individual differences, learning and instructions, Lawrence Erlbaum, Hillsdale, NJ (1993).

[37] G. Pask, Styles and strategies of learning. British Journal of Educational Psychology, 46, (1976), 128-148. http://dx.doi.org/10.1111/j.2044-8279.1976.tb02305.x

[38] R.J. Riding, Cognitive styles analysis. Birmingham, UK: Learning and Training Technology, 1991.

[39] G.H. Betts, The distribution and functions of mental imagery. New York: Teachers College, Columbia University, 1909.

[40] H.A. Witkin, C.A. Moore, D.R. Goodenough, and P.W. Cox, Field dependent and field independent cognitive styles and their educational implications. Review of Educational Research, 47, (1977), $1-64$.

[41] G. Pask, \& B.C.E. Scott, B.C.E. Learning strategies and individual competence. International Journal of Man-Machine Studies, 4 (1972) 242-253. http://dx.doi.org/10.1016/S0020-7373(72)80004$\underline{\mathrm{X}}$

[42] N. Ford, \& D. Miller, Gender differences in Internet perceptions and use. Aslib Proceedings, 48, (1996), 183-192.

[43] D. Ellis, N. Ford, \& F. Wood, Hypertext and learning styles. Final report of a project funded by the learning technology unit. Sheffield, UK: Employment Department 1992.

[44] C. Chen, Individual differences in a spatial-semantic virtual environment. Journal of the American Society for Information Science, 51, (2000), 529-542. http://dx.doi.org/10.1002/(SICI) 1097-4571(2000)51:6<529::AID-ASI5>3.0.CO;2-F

[45] F. Mampadi, S.Y. Chen, G. Ghinea, M.P. Chen, Design of Adaptive Hypermedia Learning Systems: A Cognitive Style Approach, Computers \& Education (2010)

[46] P. De Bra, G.-J. Houben, H. Wu, AHAM: A Dexter-based Reference Model for Adaptive Hypermedia. In 10th ACM conference on Hypertext and Hypermedia. Darmstadt, Germany, 1999, pp. 147-156.

[47] P. Brusilovsky, L. Pesin, and M. Zyryanov, Towards an adaptive hypermedia component for an intelligent learning environment. In Bass L.J., Gornostaev J. and Unger C. (eds.) Human-Computer Interaction. Lecture Notes in Computer Science, v. 753, SpringerVerlag, Berlin, 1993, 348-358 http://dx.doi.org/10.1007/3-54057433-6 63

[48] P. De Bra, and L. Calvi, AHA: a Generic Adaptive Hypermedia System, Proceedings of the Second Workshop on AdaptiveHypertext and Hypermedia, pp. 5-11, Pittsburgh, 1998.

\section{AUTHORS}

F. Mampadi and P.A. Mokotedi are with the department of Computer Science at the University of Botswana.

Received 3 April 2012. Published as resubmitted by the authors 7 August 2012. 